\title{
Que a escola vá bem: contribuições de João Batista de La Salle (1651-1719) para o debate contemporâneo sobre a qualidade da educação
}

\author{
The school ougt to perform well: contributions by John \\ Baptist de La Salle (1651-1719) to the contemporary \\ debateof the quality of education
}

Que la escuela va bien: contribuciones de Juan Bautista de La Salle (1651-1719) en el debate contemporáneo sobre la calidad de la educación

\section{Ângelo Ezequiel Leubet ${ }^{1}$ Jorge Alexandre Bieluczyk ${ }^{2}$ Evaldo Luis Pauly ${ }^{3}$}

\section{Resumo}

Este artigo discute a qualidade do ensino no Brasil a partir de uma revisão de literatura cotejando-a com alguns textos pedagógicos de João Batista de La Salle, o parecer CNE/CEB 08/2010 e a análise crítica de alguns de seus comentadores. Esta discussão tem por finalidade analisar a qualidade do ensino numa perspectiva lassalista com intuito de identificar conceitos pedagógicos e desafios da gestão educativa que proporcione melhores processos de ensino-aprendizagem. A partir das análises realizadas apontamos João Batista de La Salle como pai da pedagogia moderna e mentor de conceitos pedagógicos e administrativos, que possuem validade para a pedagogia contemporânea e possibilitam orientar os processos de formação com qualidade humana e cidadã. Para este fim, o artigo está orientado em três direções: a primeira é a revisão de literatura; a segunda levanta elementos para uma discussão sobre a qualidade do ensino a partir da pedagogia de La Salle e a terceira, apresenta, a título de conclusão, elementos para avançar no debate sobre a qualidade da educação.

Palavras Chave: João Batista de La Salle; Qualidade de Ensino; Gestão.

1Mestrando no PPG em Educação do Centro Universitário La Salle de Canoas/RS. E-mail: angeloleubet@outlook.com;

2 Mestrando no PPG em Educação do Centro Universitário La Salle de Canoas/RS. E-mail: Jorge.bieluczyk@lasalle.org.br;

3Doutor em Educação pela Universidade Federal do Rio Grande do Sul (2000). Coordenador do Programa de Pós graduação em Educação - Mestrado e Doutorado - do Centro Universitário La Salle - UNILASALLE de Canoas/RS. Coordenador pela Região Sul do Fórum de Coordenadores de Programas de Pós-Graduação em Educação da Associação Nacional de Pós-Graduação e Pesquisa em Educação - ANPEd (2014-2015). E-mail: evaldo@unilasalle.edu.br; 


\section{Abstract}

This article argues the quality of teaching in Brazil, departing from a literature checking, confronting it face to face both with the pedagogical writings by John Baptist De La Salle, and the concept CNE/ CEB 08/2010, and the critics by some of their commentators. This discussion aims to analyze the quality of the teaching within a Lassalian outlook trying to identify pedagogical concepts as well as the challenges of the education management that brings forth better proceedings of teaching-learning. Starting with the results of the analyzes we point out La Salle as the father of modern pedagogy and guide of pedagogical and managing concepts, that have validness for the contemporary pedagogy and give chance to give direction to the proceedings of formation with human quality and citizenship. Aiming at this, this article has been turned to four directions: The first is the revision of the literature at hand; the second, to raise up elements for a discussion on the quality of the teaching started with applying the pedagogy by La Salle; and the third, sort as conclusion, presents elements to advance in debating the quality of the Lassalian education.

Keywords: John Baptist de La Salle; Teaching Quality; Administration.

\section{Resumen:}

En este artículo se analiza la calidad de la educación en Brasil desde un cotejo de revisión de la literatura con algunos escritos pedagógicos de Juan Bautista de La Salle, el dictamen de la CNE/CEB 08/2010 y análisis crítico de algunos de sus comentaristas. Esta discusión tiene como objetivo analizar la calidad de la educación con el fin de identificar en una perspectiva lassalista con conceptos y desafíos de la gestión de la educación pedagógica para ofrecer mejores procesos de enseñanza y aprendizaje. A partir de los análisis señalamos Juan Bautista de La Salle como el padre de la pedagogía moderna y mentor de conceptos pedagógicos y administrativos, que son válidos para la pedagogía contemporánea y permiten guiar los procesos de formación con calidad humana y ciudadana. Con este fin, el artículo se orienta en cuatro direcciones: la primera es la revisión de la literatura; la segunda plantea elementos para una discusión sobre la calidad de la enseñanza de la pedagogía de la Salle y la tercera presenta la conclusión, los elementos para avanzar en el debate sobre la calidad de la educación.

Palabras clave: Juan Bautista de La Salle; Calidad de la educación; Administración 


\section{Introdução}

Todos defendem a qualidade na educação. Políticos a prometem, empresários a reivindicam, pais e mães sonham com ela, pesquisadores tentam defini-la e docentes a desejam e tentam realizá-la. Parece uma convicção praticamente unânime em nosso país. Mas, afinal qual seria o padrão de qualidade da educação, como deve ser e quanto custa uma boa escola para todas as crianças e adolescentes brasileiros? Esta resposta está formulada pelo Conselho Nacional de Educação (CNE) no Parecer n 8/2010, ainda não homologado pelo MEC. O relator, Prof. Dr. Mozart Neves Ramos, da Universidade Federal de Pernambuco, produziu um extenso Parecer sobre o que é educação de qualidade e como o sistema educacional brasileiro pode atingi-la:

Os desafios para a construção de uma educação de qualidade para todos os brasileiros passam, sobretudo, pela valorização da carreira do magistério (valorização salarial, plano de carreira, formação inicial e continuada, e condições de trabalho), financiamento e gestão da educação, e estabelecimento de padrões mínimos de qualidade para nossas escolas públicas de Educação Básica (CNE/CEB, 2010, p. 8).

A tabela abaixo segue os cálculos do CNE para financiar o custo da educação de qualidade, viabilizando o Custo Aluno Qualidade Inicial (CAQi) previsto pelos artigos 4, inciso IX4, 74 e 75 da LDB. O resultado do cálculo tem "como referência o custo total estimado por aluno, expresso em percentual do PIB per capita" (CNE/CEB, 2010, p. 43). O IBGE informa que o PIB per capita de 2014 foi de R\$27.229,00. Com esses dados é possível construir a tabela abaixo:

Tabela 1: Valor do custo aluno qualidade - CAQ - 2014

\begin{tabular}{|c|c|c|c|}
\hline Nível/Etapa da educação básica (obrigatória em 2016) & $\%$ PIB per capita & Valor anual ${ }^{5}$ & Valor mensal \\
\hline Creche & $39,0 \%$ & $10.619,00$ & 816,90 \\
\hline Pré-Escola & $15,1 \%$ & $4.111,58$ & 316,27 \\
\hline Ensino Fundamental (anos iniciais) & $14,4 \%$ & $3.920,97$ & 301,61 \\
\hline Ensino Fundamental (anos finais) & $14,1 \%$ & $3.839,28$ & 295,33 \\
\hline Ensino Médio & $14,5 \%$ & $3.948,20$ & 303,71 \\
\hline Ensino Fundamental - escola de Educação do Campo (anos iniciais) & $23,8 \%$ & $6.480,50$ & 498,50 \\
\hline Ensino Fundamental - escola de Educação do Campo (anos finais) & $18,2 \%$ & $4.955,68$ & 381,20 \\
\hline
\end{tabular}

Conforme o art. 22 da Lei № 11.494/2007 que regulamenta o Fundo de Manutenção e Desenvolvimento da Educação Básica e de Valorização dos Profissionais da Educação - FUNDEB, os recursos disponíveis para o pagamento do Magistério, no âmbito do FUNDEB, equivalem a, no mínimo, "60\% (sessenta por cento) dos recursos anuais totais dos Fundos". A possibilidade de aumento real nos salários dos professores da rede pública, portanto, vincula-se diretamente à definição política de quanto a sociedade investirá na escola para gerar a qualidade da educação que as crianças, adolescentes e suas famílias merecem receber do Estado.

A pesquisa em educação precisa superar a crença do senso comum de que a educação básica da escola estatal é ruim porque é barata e da escola privada é boa porque é cara. Boa educação é sempre cara. As crianças merecem ter a melhor educação possível porque elas têm prioridade absoluta na sociedade! A boa educação é cara e o estado brasileiro pode pagá-la pelos Impostos que arrecada. Em 2008, os impostos representavam 35,2\% do PIB nacional (IPEA, 2010, p. 9). O senso comum criado pela mídia nos convenceu de

40 art. $4^{\circ}$ da Lei $n^{0} 9.394 / 96$ (LDB) define que o "dever do Estado com educação escolar pública será efetivado mediante a garantia de”, entre outras, oferta de educação obrigatória com "padrões mínimos de qualidade de ensino, definidos como a variedade e quantidade mínimas, por aluno, de insumos indispensáveis ao desenvolvimento do processo de ensino-aprendizagem". 0 Conselho Nacional de Educação definiu esse valor, mas recebeu apoio da sociedade civil e magistério para que Ministério da Educação pudesse homologar o Parecer $n^{0} 8 / 2010$, em harmonia e colaboração com os dois outros poderes da República.

51 R 27.229,00 foi o valor do PIB per capita em 2014 conforme o IBGE (http://brasilemsintese.ibge.gov.br/pt/contas-nacionais/pib-per-capita) em 02 jun. 2015 
que se paga muito imposto. Não é bem assim: as famílias pobres pagam mais impostos que as famílias ricas, dado o caráter regressivo da tributação nacional. Apontamos dois exemplos. Primeiro: o inciso VII do art. 153 da Constituição Federal de 1988 prevê a criação de imposto sobre as "grandes fortunas", mas Congresso nunca aprovou a "lei complementar" exigida pela Constituição. Um princípio tributário republicano afirma ser justo cobrar mais de quem tem mais e menos de quem tem menos. Uma análise da estrutura tributária realizada pelo IPEA revela a injustiça e a regressividade dos impostos no Brasil:

0 total de tributos diretos pago pelas famílias que estavam no estrato de renda mais alto mostrou-se seis vezes maior do que 0 total pago pelas famílias do primeiro estrato. Porém, este fato apresentou-se insuficiente para compensar a alta desigualdade de renda, pois 0 recebimento médio mensal familiar per capita do maior estrato de rendimentos revelou-se 37 vezes superior em relação ao menor estrato. Por outro lado, os tributos indiretos mostraram-se regressivos em relação à renda líquida (isto é, a renda bruta familiar descontada a carga de tributos diretos). Para as famílias que ganhavam até dois salários mínimos, o total da carga indireta estava em torno de 27\% da renda líquida. Nas famílias cujos recebimentos médios superavam 30 salários mínimos, os tributos indiretos representaram pouco mais de 7\% de suas rendas líquidas (IPEA, 2010, p. 14-15).

A educação pode ter o financiamento que desejar, bastando inverter a regressividade injusta dos impostos em progressividade justa: que as famílias mais ricas passem a pagar $27 \%$ da sua renda em impostos, e as famílias mais pobres, 7\%. A pesquisa em educação precisa libertar-se de seus próprios medos. Um deles é o senso comum do professorado e pesquisadores que sustentam a tese estalinista de que o dinheiro público é para escola pública. Não existe escola privada e muito menos dinheiro que não seja público! A riqueza é socialmente produzida, tese que Marx herdou de Santo Agostinho. Todas as escolas de qualquer nível ou modalidade da educação nacional pertencem a um dos quatro sistemas de ensino: municipal, distrital, estadual ou federal. Estes sistemas são públicos porque estão sob a gestão de um órgão de Estado: o respectivo Conselho de Educação. Estes Conselhos estão sob a gestãopermanente da cidadania e temporária do governo eleito.

Para discutir a qualidade da educação com alguma racionalidade, é preciso libertar-nos da ilusão de que a educação brasileira é ruim porque somos um país pobre. O Brasil não é um país pobre, é um país injusto. A experiência internacional dos últimos séculos mostra que o caminho mais saudável e menos violento para uma nação superar a pobreza é a boa educação das crianças ou, em palavras de La Salle, que a "escola vá bem".

Este artigo tem por finalidade analisar a qualidade do ensino numa perspectiva lassalista com intuito de identificar boas práticas educativas que possam colaborar para a melhoria dos processos de ensinoaprendizagem. Para este fim, o artigo está orientado em três direções: a primeira é a revisão de literatura; a segunda levanta elementos para uma discussão sobre a qualidade do ensino a partir da pedagogia de La Salle e a terceira, apresenta, a título de conclusão, elementos para avançar no debate sobre a qualidade da educação a partir de La Salle, do Parecer n8/2010 CNE/CEB. Conselho Nacional de Educação/Câmara de Educação Básica e das pesquisas atuais sobre a qualidade do ensino.

\section{A qualidade do ensino nas pesquisas atuais sobre educação}

O termo qualidade de ensino comporta uma diversidade de significados, pois sua compreensão está vinculada ao tipo de educação que se deseja para formar um ideal de pessoa e de sociedade, a qual varia de acordo com os diferentes períodos, países, grupos e regiões. Sendo assim, analisamos como algumas pesquisas no Brasil abordam e discutem a temática da qualidade do ensino e quais práticas educativas se revelam mais promissoras para o alcance da desejada qualidade. Para tanto, consultamos o banco de teses da CAPES, com o fim de encontrar dissertações e teses, e a biblioteca virtual da Scielo, para buscar artigos científicos.

A pesquisa realizada na CAPES utilizando o termo "Qualidade do ensino de Educação Básica na gestão escolar" localizou 23 dissertações de mestrado acadêmico, 03 dissertações de mestrado profissional e 05 teses de doutorado, somando um total de 31 títulos encontrados. Destes, foram selecionadas 05 dissertações de mestrado acadêmico, as quais mais se aproximavam do tema da pesquisa. A pesquisa na Scielo, utilizando como descritor "Qualidade do 
ensino da Educação Básica e gestão", selecionados os filtros, Ano de Publicação: 2010 a 2014 e Idioma: Português localizou 03 artigos, dos quais apenas um foi selecionado para análise. Já com o descritor "Qualidade de ensino da Educação Básica", selecionados os filtros anteriores e Áreas Temáticas: Educação e pesquisa educacional foram encontrados 17 artigos, dos quais 03 foram selecionados para análise. Um artigo apareceu na pesquisa com os dois descritores. Abaixo, seguem os resultados das pesquisas sobre qualidade do ensino de Paz (2011), Klauck (2012), Amorim (2011), Silva (2012), Salvetti (2011), Nardi, Schneider e Rios (2014), Soares e Xavier (2013) e Marchelli (2010).

A pesquisa realizada por Paz (2011), com o objetivo de analisar as principais causas que desencadearam, segundo o Ministério da Educação, a melhoria da qualidade da educação em um município paulista, o qual obteve, em nível nacional, a maior evolução do Índice de Desenvolvimento da Educação Básica (IDEB), entre 2005 e 2007, revelou que "[...] a verificação do rendimento escolar por meio do IDEB não pode fundamentarse, meramente, em indicadores quantitativos, sem investigações profundas do ambiente escolar, clima organizacional, práticas pedagógicas e processos democráticos de gestão [...]" (PAZ, 2011, p. 118). Ou seja, a concepção de qualidade revelada a partir da gestão educacional e das práticas educativas deste município aponta para a necessidade de levar em consideração aspectos extra e intraescolares.

O autor ressalta que conceituar qualidade é uma tarefa complexa e que não existem consensos sobre o melhor caminho a seguir. Destaca a necessidade de se transpor a supremacia ideológica da quantidade a partir da abertura para as diferentes dimensões que possam influenciar para uma educação de qualidade. A pesquisa identificou um conjunto de elementos que interferiram na qualidade da educação de acordo com os atores educativos. Tais elementos podem ou não interferir em outras realidades:

[...] investimentos financeiros em educação, construção de unidades escolares pequenas, relação satisfatória entre o número de crianças por professor, fortalecimento da carreira do magistério e incentivos salariais por aumento da titulação acadêmica, estabilidade do corpo docente e dedicação exclusiva a uma única unidade escolar, os atores educativos acreditaram proporcionar à comunidade um ensino de qualidade, mas que, em suma, não tem nada de diferente, a não ser o comprometimento com o processo educativo (PAZ, 2011, p. 178).

Klauck (2012) realizou estudo empírico para compreender em que consiste a qualidade para uma escola pública que teve desempenho positivo atestado pelas avaliações nacionais e pelo IDEB, sendo destaque nos rankings nacional e estadual. A análise das ações educativas e da avaliação dos atores escolares e pais de alunos resultou no entendimento de que a qualidade do ensino na escola está relacionada com a estabilidade dos professores, a organização da escola, o trabalho de equipe, a articulação com pais e a motivação dos alunos para o estudo.

Conforme a autora, as iniciativas para o desenvolvimento de estudos que investigam as boas práticas das escolas estão num crescente, o que favorece a determinação de fatores que caracterizam experiências de sucesso. Quanto à qualidade do ensino, reforça que "[...] é impossível ser delimitada de maneira exclusivamente quantitativa e em termos de recursos mínimos. Há dimensões não mensuráveis do contexto escolar que precisam ser consideradas, quando se trata da qualidade do ensino" (KLAUCK, 2012, p. 33).

Por sua vez, Amorim (2011) analisou a literatura atual e as políticas educacionais que trazem como assunto principal a qualidade da educação brasileira e realizou entrevistas com técnicos e secretários de educação dos municípios de Dourados e Ponta Porã localizados nos Estado do Mato Grosso do Sul, com a intenção de compreender a concepção de qualidade que vem se efetivando no contexto brasileiro com a instituição do Plano de Desenvolvimento da Educação (PDE).

Ressalta que o assunto da qualidade do ensino atualmente tem se revelado complexa e que existe certa banalização do tema em meio a incessantes discursos, baseados nos mais diversos vieses teóricos e políticos, os quais pouco têm contribuído para a efetiva melhoria da educação no país. Afirma que:

As planificações inseridas pelo governo federal são de caráter estratégico e de ordem desenvolvimentista com os preceitos gerenciais bem acentuados. Essa característica tem levado as políticas públicas da educação a se focarem estritamente nos resultados, ou seja, minimiza-se o processo de ensino e aprendizagem que é constituído de inícios, meios e fins. Uma prova disso é o IDEB que se configura como um quantitativo e vem sendo considerado sinônimo de qualidade (AMORIM, 2011, p. 141). 
Silva (2012), a partir de uma análise quantitativa, por meio de dados obtidos no sítio do INEP, e de outra qualitativa, com entrevistas a atores educativos, procurou elucidar as ações adotadas pelas escolas de séries iniciais do Ensino Fundamental da rede pública de Juiz de Fora, Minas Gerais, que resultaram numa significativa evolução do IDEB entre 2007 e 2009. Procurou, também, verificar a representação que o professor tem sobre essa avaliação, suas funções e como reagem a elas.

Conforme a autora, as ações que resultaram na evolução do IDEB nessa realidade "[...] são pautadas numa proposta pedagógica centrada nos alunos, em suas dificuldades e capacidades de aprendizagem" (SILVA, 2012, p. 75). Ainda observa que, de acordo com os professores, a melhora do resultado do IDEB é consequência do trabalho comprometido dos atores escolares, que não está somente direcionado para o aumento do IDEB.

Ao se referir ao tema da qualidade da educação, afirma que melhorá-la é um dos maiores objetivos tanto dos sistemas de ensino, como dos pesquisadores em educação. Também destaca a necessidade de levar em consideração os fatores internos e externos que interferem no processo de avaliação, desempenho e qualidade do ensino.

Salvetti (2011) analisa a qualidade da educação escolar, na dimensão da gestão democrática, por meio de um estudo de caso na EMEB Alfredo Naime, localizada no município de Bebedouros-SP, a qual passou pelo programa Indicadores de Qualidade de Ensino (INDIQUE).

$\mathrm{Na}$ discussão sobre a qualidade de ensino, esse autor observa que esta não pode ser tratada apenas por termos quantitativos, pois deixaria de considerar importantes fatores subjetivos e objetivos da educação, como, também, de verificar e desenvolver os processos educativos. Afirma ser necessário atentar para um conjunto de qualidades como:

[...] a disposição de recursos não mínimos, mas suficientes para oferecer os insumos indispensáveis às múltiplas necessidades escolares, boas condições de trabalho, de materiais, de infraestrutura, de gestão, entre outros, capazes de proporcionar e induzir as escolas à concretização de seus objetivos pedagógicos, à realização de uma função social inclusiva e transformadora, à construção de sujeitos engajados técnica, pedagógica e politicamente (SALVETTI, 2011, p. 22).

Nardi, Schneider e Rios (2014), a partir de pesquisa feita sobre a qualidade do ensino, concluem que as escolas pesquisadas reconhecem seus problemas de maior expressão e propõem ações estratégicas, que nem sempre estão em sintonia com as carências da escola. Os autores não encontraram correspondência uniforme entre ações nessa linha e alcance de melhores índices e indicadores oficiais. As pesquisas também revelaram a "[...] adoção de material pedagógico apostilado, como destaque ao alcance de melhores índices e indicadores educacionais" (NARDI; SCHNEIDER; RIOS, 2014, p. 388), o que pode estar relacionado ao fato de os sistemas dessa natureza vincularem aos seus produtos "[...] ações, como formação continuada de professores e aportes no campo da gestão escolar, especialmente no campo pedagógico" (NARDI; SCHNEIDER; RIOS, 2014, p. 388).

Marchelli (2010, p. 561), ao refletir sobre a avaliação da qualidade do ensino, realizada através de provas aplicadas para medir o desempenho dos estudantes, destaca que "[...] a qualidade deve ser considerada em termos representados pelos ganhos sociais da universalização do ensino e não unicamente pelas notas obtidas nas provas". Segundo o autor, "[...] no âmbito da legislação política e da literatura de apoio técnico, criadas respectivamente para regular e subsidiar os processos de avaliação, surge a questão dos indicadores de qualidade como um ponto fundamental (MARCHELLI, 2010, p. 581)", porém, é necessário "[...] interpretar os resultados de forma que eles agreguem também os ganhos sociais decorrentes da aplicação de políticas públicas inclusivas, como é o caso da não-repetência, que conseguiu corrigir as graves distorções do fluxo escolar" (MARCHELLI, 2010, p. 581).

Soares e Xavier (2013) destacam o uso cada vez mais frequente do desempenho dos alunos nas avaliações externas da aprendizagem, como meio de orientar as políticas educacionais. Ressaltam que "[...] o IDEB tornouse a forma privilegiada e frequentemente única de se avaliar a qualidade da educação básica brasileira e, por isso, tem tido grande influência no debate educacional no país" (SOARES; XAVIER, 2013, p. 904). A introdução 
do IDEB traz em pauta, "[...] a ideia de que, hoje os sistemas educacionais brasileiros devem ser avaliados não apenas pelos seus processos de ensino e gestão, mas principalmente pelo aprendizado e trajetória escolar dos alunos" (SOARES; XAVIER, 2013, p. 904). Os autores entendem o IDEB, como "[...] um primeiro passo para o processo de reflexão interna nas escolas, na busca de melhores e mais efetivas práticas pedagógicas que vão permitir aos seus alunos aprender o que precisam para uma vida digna e feliz" (SOARES; XAVIER, 2013, p. 921).

Em síntese, este estado da arte será retomado no quadro 2, para fins comparativos com a proposta lassalista.

\section{A qualidade do ensino segundo La Salle}

O Guia das Escolas Cristãs, principal obra pedagógica do século XVII na França, conforme Tardif e Gauthier, também calcula quanto custa uma educação de qualidade. Esta obra coletiva, liderada por São João Batista de La Salle, canonizado pela Igreja Católica Apostólica Romana e declarado por ela como patrono dos professores, transformou a educação francesa no século XVII. Sacerdote e doutor em Teologia, La Salle, junto com os professores que compunham o Instituto dos Irmãos das Escolas Cristãs, encontrou na educação a melhor forma de viver sua vocação cristã, tornando-se uma referência tanto para a educação católica quanto para a pedagogia laica moderna no que se refere à educação de crianças e adolescentes, sobretudo pobres, devido ao desenvolvimento e aperfeiçoamento de métodos de ensino-aprendizagem que contribuíram significativamente para a revolução da educação inicial. Apesar disso, La Salle permanece relativamente desconhecido na historiografia da educação no Brasil. Conforme Tagliavini e Piantkoski(p. 24, 2013): "Há uma lacuna muito grande sobre a obra educacional de La Salle na bibliografia e mesmo nas dissertações e teses nos Programas de Educação no Brasil”.

Gauthier e Tardif reconhecem a importância de La Salle e dos Irmãos professores na criação da pedagogia moderna, fundamentada no método e organização do ambiente escolar planejado pedagogicamente por mestres e gestores. Estes autores canadenses reconhecem que o Instituto dos Irmãos das Escolas Cristãs resolveu o problema da qualidade da educação no século XVII, que era "como ensinar a grupos de crianças (do povo) durante um período contínuo em um local dado e fazendo de modo que elas aprendam mais, mais depressa e melhor?" (2010, p. 13, grifos do autor). Nesse sentido, os discípulos de La Salle são importante referência para a discussão sobre a qualidade do ensino, pois estão entre os pioneiros da pedagogia moderna que revolucionaram a qualidade da educação francesa no século XVII: criaram regras para medir a qualidade educacional, para controlar os processos de ensino e aprendizagem e para garantir o exercício profissional da docência. Sistematizaram a reflexão sobre a prática docente que caracteriza a pedagogia moderna e tornaram possível a universalização de uma educação eficaz e eficiente para as crianças e adolescentes franceses e de outros países europeus do século XVIII.

Os Irmãos e demais professores vinculados à Rede La Salle, herdeiros da pedagogia lassalista, procuram estar atentos às mudanças no cenário da educação atual e continuam buscando as melhores respostas para os problemas da educação contemporânea. Os diretores/gestores lassalistas de hoje propõem-se a encontrar os melhores meios pedagógicos para alcançar a qualidade do ensino. Inspiram-se, para isso, no exemplo do fundador das Escolas Cristãs, que insistia no cuidado para que a escola funcionasse sempre bem e que constantemente se avaliasse a eficácia das suas práticas pedagógicas (LA SALLE, 2012, v. 1).

La Salle viveu e desenvolveu sua obra educacional no contexto francês do século XVII e, mais especificamente, dentro de um universo clerical. Sob a influência cultural da cristandade, encontrou nas escolas um meio de colaborar para a salvação das crianças e jovens do seu tempo e, ainda, remediar o cenário de pobreza, de mendicância e de precariedade econômica. A marca de suas escolas era o ensino eficaz e eficiente, isto é, o que hoje conceituamos como educação de qualidade.

La Salle superou a cristandade porque entendia a educação como universal, ouseja, tinha a convicção de 
que a Escola Cristã era um direito de todos e buscou criar meios para que todos tivessem acesso a ela: assumiu a gratuidade como princípio fundamental; intentou persuadir as famílias a colocar seus filhos nas escolas, mostrando as vantagens dessa decisão; tornou a escola atrativa e qualificou e valorizou a profissão docente; projetou uma escola que atendesse às necessidades dos pobres; e adotou o modo simultâneo de ensino, que permitiu o atendimento de um número maior de crianças e jovens em idade escolar (HENGEMÜLE, 2007). Criou a primeira escola normal para formação de professores na Europa (SAVIANI, 2009).

A educação oferecida nas Escolas Cristãs era concebida para atender às necessidades dos mais pobres, que precisavam de um método diferenciado, voltado para uma prática, a qual deveria favorecer a formação para a empregabilidade e a inclusão no ambiente social. La Salle pensou numa educação para os filhos do povo, acreditando que, ao ensinar-Ihes a leitura, a escrita, o cálculo, a catequese e as boas maneiras, as crianças seriam "capazes de tudo" (LA SALLE, 2012, v. 3, p.197). Profissionalizou professores populares para a oferta do ensino gratuito; forneceu os materiais necessários para que as crianças pudessem frequentar as aulas com proveito e criou programas escolares à sua medida. Enfim, "[...] a escola lassalista realizou trabalho transformador de pessoas e, em consequência, de melhoramento da sociedade" (HENGEMÜLE, 2007, p. 61); deu aos filhos do povo a nova esperança de que, a partir da boa escolarização, teriam condições de aprender um ofício e elevar seu nível social.

A educação era centrada no aluno. Em outras palavras, La Salle pensava a escola a partir das necessidades dos alunos. Para isso, tanto a direção quanto os professores colocavam-se a serviço da aprendizagem deles: "Numa palavra, não perdestes o tempo que, em vossa profissão, já não é vosso, mas de vossos alunos? Todo ele deve ser utilizado em proveito das crianças, assim como o servo deve usá-lo todo a serviço de seu senhor" (LA SALLE, 2012, v. 2-B, p. 217). La Salle orientava seus professores a conhecer bem o aluno para poder atendê-lo de modo mais adequado e, por isso, fez duplo esforço:

Primeiro, de conhecer o aluno, utilizando, para isso, vários meios, entre os quais, sobretudo, os 'catálogos', ou registros. Segundo, de oferecer ao educando atenção diferenciada e mesmo personalizada, com a criação de obras distintas para clientelas diferentes, a atenção adequada às características do educando, 0 aproveitamento de elementos do modo individual de ensino, junto ao modo simultâneo, o contato e diálogo pessoal, a possibilidade de avanç̧os de acordo com o ritmo de cada um (FOSSATTI; HENGEMÜLE; CASAGRANDE, 2011, p. 107).

Os alunos deveriam receber "[...] a educação que lhes convém" (LA SALLE, 2012, v. 2-A, p. 18). Em razão disso, La Salle criou diferentes tipos de escolas que atendiam públicos específicos: as Escolas Cristãs primárias, que proporcionavam boa base para a vida cristã, cidadã e profissional; a Escola Dominical, para jovens que trabalhavam durante a semana; o Noviciado, para candidatos a professores Irmãos; os Seminários de Mestres do Interior, para formar professores leigos para as escolas rurais e o Pensionato de Saint-Yon, destinado a filhos de burgueses, comerciantes e "industriais". Todas elas adotavam processos escolares bem conduzidos:

[...] o preparo humano da pessoa humana em geral e 0 do cristão, do cidadão e do profissional em particular, não é realizado só pelos conteúdos ensinados, as experiências vividas, os exercícios executados, as disposições e habilidades desenvolvidas; é feito também pelo modo como se conduz o processo de ensinar e aprender (HENGEMÜLE, 2007, p. 201).

Para ter êxito no seu empreendimento, La Salle atraiu alunos para suas escolas, conservou-os nas salas de aula o tempo suficiente para aprenderem bem as lições e os fez progredir. Conseguiubons resultados, pois

[...] imprimió un sentido muy realista y práctico a los programas escolares: prioridad a los aprendizajes básicos para la vida, graduación y comprobación sistemática de los datos adquiridos, optimización del tiempo, aprendizaje simultánea, alfabetización en el idioma materno (MORALES, 1990, p. 275).

La Salle tinha um talento natural para "[...] colocar em andamento a instituição escolar de modo criativo ou transformador, organizado e eficiente" (HENGEMÜLE, 2007, p. 217). Implantou nas suas escolas os melhores métodos e técnicas existentes na época e, junto com os professores, refletiu sobre a prática educativa, buscando soluções adequadas para os problemas que se apresentavam: confeccionou textos escolares, cartazes para o aprendizado das letras e sílabas e das operações de aritmética, móveis que favoreciam o trabalho escolar, etc., ideias inteligentes que qualificaram o ensino e tornaram suas escolas eficazes e eficientes. 
Outro fator determinante para o sucesso das Escolas Cristãs era a vida comunitária dos educadores. Os Irmãos formavam uma comunidade religiosa em torno da escola, vivendo em comunhão em uma residência comum: "Os Irmãos tinham um só coração e um só espírito. Viviam em profunda paz, ajudando-se mutuamente com grande caridade terna e compassiva. Tudo thes era comum, nenhum interesse pessoal dividia sua atenção [...]" (MAILLEFER, 1991, p. 70)6. O trabalho em equipe favorecia o bom andamento das escolas e a melhoria do ensino, pois partilhavam as experiências, selecionavam as melhores práticas e os professores mais experientes acompanhavam os docentes em formação, transmitindo-lhes suas experiências pedagógicas. Desta forma, consolidavam seus métodos de ensino que imprimiam um estilo singular para sua rede de escolas.

\section{Que a escola vá bem: elementos para uma discussão sobre a qualidade do ensino a partir da pedagogia de La Salle}

O resultado da análise da qualidade do ensino a partir das pesquisas atuais sobre educação e de alguns escritos de La Salle e de comentadores da sua obra revelam que os fatores relevantes para alcançar a qualidade do ensino são muito parecidos. Dadas as diferenças de cada época, pode-se dizer que os conceitos de qualidade de ensino de La Salle, com o devido tratamento científico e hermenêutico, podem continuar inspirando o fazer pedagógico das escolas lassalistas e demais escolas. Abaixo segue um quadro ${ }^{7}$ comparativo do parecer $\mathrm{CNE} /$ CEB n 8/2010, das pesquisas atuais sobre educação e de La Salle em torno da questão qualidade do ensino:

Tabela 2: A qualidade da educação

\begin{tabular}{|c|c|c|}
\hline $\begin{array}{c}\text { Segundo o Parecer do CNE/CEB N } \\
\text { 8/2010 }\end{array}$ & $\begin{array}{l}\text { Nas pesquisas atuais } \\
\text { sobre educação }\end{array}$ & Segundo La Salle \\
\hline $\begin{array}{l}\text { Art. } 7^{0} \text { e } 8^{\circ} \text { ver anexo } 1 \text { com o cálculo } \\
\text { do custo aluno qualidade inicial. "Em } \\
\text { resumo, os fatores que mais impactam } \\
\text { no cálculo do CAQi são: 1) tamanho } \\
\text { da escola/Creche; 2) jornada dos } \\
\text { alunos (tempo parcial versus tempo } \\
\text { integral); 3) relação alunos/turma ou } \\
\text { alunos/professor; 4) valorização dos } \\
\text { profissionais do magistério, incluindo } \\
\text { salário, plano de carreira e formação } \\
\text { inicial e continuada" (p.19). }\end{array}$ & $\begin{array}{c}\text { Investimentos em } \\
\text { educação (PAZ, } \\
\text { 2011; SALVETTI, } \\
\text { 2011). }\end{array}$ & $\begin{array}{l}\text { Gratuidade das Escolas: seu financiamento não depende do } \\
\text { pagamento dos alunos. } \\
\text { "Não sei, meu Senhor, se esteve atento a que a casa alugada } \\
\text { disponha de duas salas contíguas para as aulas, por ser isto } \\
\text { obrigatório para nossos Irmãos. } \\
\text { Se não teve presente esse cuidado, pediria que o leve em conta, } \\
\text { alugando algumas classes contíguas antes que nossos Irmãos } \\
\text { iniciem as atividades" (LA SALLE, 2012, v. 1, p. 207). }\end{array}$ \\
\hline $\begin{array}{l}\text { "Art. } 4^{0} \text { Deve-se implementar jornada de } \\
40 \text { (quarenta) horas semanais para os } \\
\text { profissionais da educação, em tempo } \\
\text { integral em uma mesma escola, com } \\
\text { demais condições adequadas de trabalho } \\
\text { e infraestrutura" (p.41) "Os desafios } \\
\text { para a construção de uma educação de } \\
\text { qualidade para todos os brasileiros exige } \\
\text { que os sistemas de ensino, em regime } \\
\text { de colaboração, promovam a valorização } \\
\text { dos profissionais da educação, o } \\
\text { financiamento e a gestão da educação" } \\
\text { (p.41) }\end{array}$ & $\begin{array}{c}\text { Estabilidade do } \\
\text { corpo docente (PAZ, } \\
\text { 2011; KLAUCK, } \\
\text { 2012). }\end{array}$ & $\begin{array}{l}\text { O voto de estabilidade. } \\
\text { "Por isso, prometo e faço voto de obediência, tanto ao Corpo desta } \\
\text { Sociedade, quanto aos Superiores. Tais votos, tanto de associação } \\
\text { como o de estabilidade na referida Sociedade e o de obediência, } \\
\text { prometo guardar inviolavelmente por toda a minha vida" (LA SALLE, } \\
\text { 2012, v. 1, p. 45). } \\
\text { "Amarão ternamente todos os seus alunos" (LA SALLE, 2012, v. } \\
\text { 2-A, p.29). }\end{array}$ \\
\hline
\end{tabular}

6Um dos primeiros biógrafos de La Salle reconhecido pela historiografia da educação. (SAUVAGE; CAMPOS, 2013).

7Quadro elaborado pelos autores. 


\begin{tabular}{|c|c|c|}
\hline $\begin{array}{c}0 \text { parecer não apresenta nenhuma } \\
\text { mençãa sobre o compromisso da família } \\
\text { no processo educativo. }\end{array}$ & $\begin{array}{l}\text { Comprometimento } \\
\text { dos pais, alunos e } \\
\text { professores com a } \\
\text { qualidade (KLAUCK, } \\
\text { 2012; SILVA, 2012). }\end{array}$ & $\begin{array}{c}\text { "O Irmão Diretor não admitirá criança para a escola que não Ihe } \\
\text { seja apresentada pelo pai ou mãe, ou pela pessoa com a qual mora, } \\
\text { ou por alguém aparentado com ele, ou de idade razoável, e que se } \\
\text { possa ter certeza de que vem da parte deles" (LA SALLE, 2012, v. } 3 \text {, } \\
\text { p. 252). } \\
\text { "Ao se admitir algum aluno na escola, se exigirá dos pais e do aluno } \\
\text { que tenha todos os livros necessários, e um livro de orações [...]. } \\
\text { Que seja assíduo à escola, nunca faltando sem autorização; que seja } \\
\text { pontual em estar todos os dias na escola, de manhã às 7h30, e a } \\
\text { uma hora depois do meio-dia" (LA SALLE, 2012, v. 3, p. 253). } \\
\text { "Se tendes com eles a firmeza de pai para tirá-los e afastá-los do } \\
\text { mal, deveis ter-lhes também a ternura de mãe para acolhê-los e } \\
\text { fazer-lhes todo bem que depende de vós" (LA SALLE, 2012, v. 2-b, } \\
\text { p. 232). }\end{array}$ \\
\hline $\begin{array}{l}\text { CAQi calcula o investimento centrado } \\
\text { por aluno. }\end{array}$ & $\begin{array}{l}\text { Proposta pedagógica } \\
\text { centrada nos alunos, } \\
\text { em suas dificuldades } \\
\text { e capacidade de } \\
\text { aprendizagem } \\
\text { (SILVA, 2012). }\end{array}$ & $\begin{array}{l}\text { Educação centrada no aluno e em suas necessidades. } \\
\text { "[...] estando os meninos da manhã a tarde, sob a direção dos } \\
\text { mestres, estes possam ensinar-lhes a bem viver,[...]dando-lhes, } \\
\text { assim, a educação que Ihes convém”.(LA SALLE, 2012, v. 2-A, p. } \\
\text { 18) } \\
\text { "É necessário proceder de maneira que os alunos saiam sempre } \\
\text { satisfeitos da escola, de modo a não poderem dizer aos pais nada } \\
\text { capaz de os desgostar” (LA SALLE, 2012, v. 3, p. 305). }\end{array}$ \\
\hline $\begin{array}{l}\text { "sem bons professores não teremos } \\
\text { bons alunos"(p.9). }\end{array}$ & $\begin{array}{l}\text { Formação } \\
\text { continuada de } \\
\text { professores e } \\
\text { aportes no campo } \\
\text { da gestão e do } \\
\text { pedagógico (NARDI; } \\
\text { SCHNEIDER; RIOS, } \\
\text { 2014). }\end{array}$ & $\begin{array}{c}\text { Atenção a formação dos professores e o trabalho em equipe. } \\
\text { "A formação dos novos mestres consiste em duas coisas: } 1 . \\
\text { Eliminar nos novos mestres o que eles tem e não devem ter; } 2 \text {. } \\
\text { Fazer-lhes adquirir o que lhes falta e que Ihes é muito necessário } \\
\text { ter." (LA SALLE, 2012, v. 3, p. 291). } \\
\text { "Observa-se que a finalidade do livro(Guia das Escolas) é a segurar } \\
\text { a unidade de ação em todas as escolas cristãs do Instituto fundado } \\
\text { por São João Batista de La Salle, e que a todo mestre jovem se } \\
\text { ensinava a dar aula segundo as normas do Guia” (LA SALLE, 2012, } \\
\text { V. 3, p. 11, Grifo Nosso). } \\
\text { "Tanto quanto possível, colocará um mestre novo junto a outro que } \\
\text { desempenha bem o seu dever" (LA SALLE, 2012, v. 3, p. 305). } \\
\text { "É necessário estudar muito o temperamento, os hábitos e as } \\
\text { inclinações dos meninos para poder lidar com eles da maneira } \\
\text { adequada" (LA SALLE, 2012, v. 3, p. 305). } \\
\text { "0 formador deverá ter o cuidado de levar o mestre em formação } \\
\text { a concluir tudo o que tiver começado; mesmo o auxiliará nisto, se } \\
\text { necessário" (LA SALLE, 2012, v. 3, p. 304). } \\
\text { "Esforce-se, por favor, para ter atitudes estimuladoras e faça que } \\
\text { um de seus principais cuidados seja fomentar a união entre seus } \\
\text { Irmãos [professores]" (LA SALLE, 2012, v. 1, p. 173). }\end{array}$ \\
\hline $\begin{array}{l}0 \text { parecer contempla o custo de projetos } \\
\text { de ações pedagógicas. }\end{array}$ & $\begin{array}{c}\text { Busca de melhores } \\
\text { e mais efetivas } \\
\text { práticas pedagógicas } \\
\text { (SOARES; XAVIER, } \\
\text { 2013). }\end{array}$ & $\begin{array}{l}\text { Introdução dos melhores métodos e técnicas de ensino existentes } \\
\text { na época. } \\
\text { "Ensinastes, com todo esmero, aos que estão aos vossos cuidados, } \\
\text { os conhecimentos humanos que são de vossa obrigação, tais como: } \\
\text { a leitura, a escrita e todo o restante? Se, durante este ano, não foi } \\
\text { assim, haveis de dar rigorosa conta a Deus, não só do vosso tempo, } \\
\text { mas também do alimento e de tudo o que vos foi fornecido para } \\
\text { as necessidades da vida, porque a obediência, ao prover-vos do } \\
\text { necessário, teve este objetivo" (LA SALLE, 2012, v. 2-B, p. 214). } \\
\text { "Enquanto um aluno realizar a operação de sua lição, o mestre } \\
\text { Ihe fará diversas perguntas referentes à mesma, para levá-lo a } \\
\text { compreendê-la e retê-la melhor. Caso o mestre utilize termos que } \\
\text { o aluno não entenda, isto é, termos próprios da aritmética, ele lhos } \\
\text { explicará todos e fará com que os repita antes de passar adiante" } \\
\text { (LA SALLE, 2012, v. 3, p. 87). }\end{array}$ \\
\hline
\end{tabular}


Quando tratamos da pedagogia lassalista, percebemos que ela é constituída por três elementos técnicos relacionados ao bom andamento da escola: a organização, os ambientes físicos e a didática. Essa tríade permite o fazer pedagógico, bem como avaliá-lo numa dimensão que atualmente chamamos de qualidade de ensino. A operacionalização das técnicas e o bom êxito no âmbito escolar é para La Salle uma questãoestratégica do seu instituto. Algumas análises do Guia das Escolas Cristãs sobre a necessidade de evitar a evasão escolar remetem diretamente para a qualidade do profissional que deve ser "capaz de desincumbir-se adequadamente de seu dever e de ensinar bem as crianças"; por outro lado, a escola deve considerar que "a capacidade dos mestres não é igual", razão pela qual a direção deve "[...] adequar o número de alunos à capacidade dos mestres, para que estes possam ensinar bem" (LA SALLE, 2012, v.3, p. 198).

Para que a escola vá bem, os elementos técnicos dispostos nas áreas administrativas e pedagógicas necessitam estar conectados na concretização da proposta pedagógica, que é possibilitada pela práxis do diretor/gestor. Nesse sentido, é possível notar um papel central da figura do diretor/gestor em busca da qualidade pedagógica. Por sua vez, os diretores eram membros da comunidade escola e indicados pelo superior geral, escolhido em assembleia. Conforme La Salle (2012, v. 3, p. 243), o diretor/gestor "Permanecerá na mesma escola, do começo ao fim, e estará atento a tudo o que se passar em todas as classes. Cuidará para que as regras e práticas da escola sejam observadas exatamente sem mudança, nem alteração nenhuma". As mudanças aconteciam por decisão coletiva, no retiro anual dos educadores, que avaliava a prática docente.

A seguir, trazemos para a discussão pressupostos lassalistas que foram compartilhados e aprofundados no desenvolvimento da pedagogia moderna no âmbito da qualidade educacional. Sabemos das críticas realizadas ao Guia das Escolas Cristãs, porém compreendemos que essas são realizadas com foco em práticas de um tempo e um espaço, e não ao conceito em si que nos permite refletir e reelaborá-lo de acordo com o nosso tempo. Neste sentido, podemos notar que a qualidade da escola de La Salle é construída sob o pressuposto da boa gestão escolar e do pedagógico, que garantem o bom andamento das atividades e a emancipação das crianças e jovens.

\section{Pressuposto da Boa Gestão Escolar}

O pressuposto da boa gestão escolar é nítido na pedagogia lassalista, sendo responsabilidade do diretor/ gestor aplicá-lo no cotidiano escolar. Neste sentido, o diretor/gestor é o empreendedor da universalização do ensino por meio de uma instituição escolar atrativa e inclusiva, em que nada é improvisado. Pelo contrário, as atribuições são definidas com clareza no Guia das Escolas Cristãs, visando à concretização dos objetivos e à eficiência do processo de ensino-aprendizagem. Weschenfelder (2015, p. 80) destaca que:

No Guia das Escolas Cristãs de La Salle sobressai a preocupação e o zelo para que a escola alcance seus objetivos, tenha eficiência como obrigação fundamental para que alcance eficácia, sempre visando à formação esmerada dos alunos em vista do sucesso futuro deles.

A preocupação com a organização é um segundo aspecto da boa gestão da escola lassalista. A disponibilidade de materiais didáticos, religiosos e usuais da operação da infraestrutura, a limpeza, as boas condições dos prédios, mobiliário adequado às crianças: "Os bancos das escolas devem ter diversas alturas, a saber: de 8,10,12,14 e 16 polegadas, e comprimento 12 a 15 pés, tudo encaixado" (LA SALLE, 2012, v. 3,p. 235236), os recursos financeiros para cumprir com as obrigações, o respeito recíproco entre docentes e discentes, as regras determinadas pelo diretor/gestor, a vivência das boas maneiras, etc. são características de uma escola com foco na formação integral e integradora. Vale ressaltar que a organização expressa na disciplina e no cumprimento das ordens é mediada pela dimensão do afeto do professor. Assim orienta La Salle (2012, v. 2-B, p. 232), "[...] se tendes para com os alunos a firmeza de pai para tirá-los e afastá-los do mal, deveis ter-lhes também a ternura de mãe para atraí-los e fazer-lhes todo o bem que depende de vós". 
Um terceiro elemento administrativo da boa gestão escolar é o cuidado com o mestre ou com o colaborador, pois, para que a escola vá bem, os alunos necessitam aprender e estes só aprendem se os professores os conhecem bem, são competentes e fraternos no uso da firmeza e ternura. Nesse âmbito, La Salle busca instruir os seus mestres dentro de uma dimensão prática do que devem ou não fazer na condução do fazer pedagógico.

O cuidado com os mestres na perspectiva lassalista exige uma atenção integral e próxima. É nesse sentido que La Salle foi levado a tomar uma decisão radical na sua vida ao abandonar o status da nobreza e assumir, por meio da associação com os mestres, a simplicidade e a missão de transformar vidas através da educação. Ao passar a viver com os mestres, La Salle iguala-se em condição e consegue responder com mais eficácia às necessidades deles.

Para que a escola vá bem, La Salle aponta um quarto elemento da gestão, ou seja, a centralidade da escola no aluno. Conforme Hengemüle (2011, p. 112),

Primeiro, porque o sonho de La Salle e de tantos outros educadores de que "a escola vá bem" não se realiza, primordialmente, quando vão bem a Direção, os professores e funcionários, com seus interesses e, até, suas comodidades, mas quando quem vai bem é 0 aluno, quando ele progride, aprende e se forma como pessoa. E também porque nem sempre o mais desejável é que ela realize o desejo, quando não, a ambição dos pais, mas que ofereça aos alunos o que eles realmente necessitam em seu presente e os prepare, tanto quanto isto é hoje possível, para seu futuro.

Em segundo lugar, a atenção ao aluno como individualmente é mesmo uma exigência demandada pela própria natureza do ato de aprender e pelas múltiplas circunstâncias que nele intervêm.

O resultado da aprendizagem dos alunos torna-se um indicador para a avaliação da qualidade e para o bom desempenho da escola. Não é por acaso que La Salle coloca o aluno numa posição central, voltando todas as ações da escola para o melhor desempenho físico, cognitivo e espiritual dos estudantes. Dessa forma, a gestão da escola lassalista é organizada para não desvirtuar este princípio, isto é, para manter um constante relacionamento com o cliente, conforme a linguagem comercial dos dias de hoje.

Portanto, podemos perceber que a gestão da escola lassalista está voltada para a qualidade. E qualidade, para La Salle, no âmbito da gestão, é organizar a formação dos professores, os processos pedagógicos, a infraestrutura e os materiais necessários para a aprendizagem eficaz do aluno. Escola em que o aluno não assimila conhecimento útil para a vida é escola que não vai bem, sem qualidade, ineficaz.

\section{Pressuposto Pedagógico}

No ponto anterior vimos que a gestão tem um papel fundamental para garantir o bom andamento da escola. No entanto, isolada do pressuposto pedagógico, ela acaba se esvaziando. Aqui dois elementos são centrais na perspectiva lassalista, para dar continuidade na reflexão sobre qualidade: 1) a formação dos professores; e 2) os aspectos metodológicos.

Para La Salle, a escola que tiver bons professores terá bons resultados dentro de sala de aula. Acolhe os mestres em sua casa e Ihes dá suporte intelectual,pedagógico e espiritual para estarem em condições de conduzir as crianças e os jovens no caminho da salvação. Em outros termos, para que estes possam transcender a realidade social, cultural, econômica, moral e espiritual em que se encontram. Aprofundando essa iniciativa, criou a primeira escola normal, assim como é entendida modernamente. Nela, ensinam-se aspectos metodológicos e pedagógicos, boas maneiras, procedimentos para corrigir atitudes docentes inadequadas, etc. "A formação dos novos mestres consiste em duas coisas: 1. Eliminar nos novos mestres o que eles têm e que não devem ter; 2) fazer-Ihes adquirir o que lhes falta e que lhes é muito necessário ter." (2012, v. 3, p. 291).

Moldar os mestres para o desempenho em favor da missão educativa é considerado o principal papel de La Salle dentro da obra que realizou. Para ele, o bom andamento da escola e o sucesso desta dependem de bons mestres, ou seja, de professores capacitados e motivados para atrair os alunos através da gratuidade do ensino 
e para fidelizá-lospor meio da boa instrução, da ternura, da ausência, praticamente, de castigos, a participação intensa dos alunos no processo educativo.

A quarta razão por que os alunos se ausentam da escola é por terem pouca afeição ao mestre, que não é atraente, não sabe como conquistá-los; que tem exterior fechado e rude; que os afugenta, grita com eles ou bate neles facilmente; e que, em toda circunstância, os únicos recursos a que apela são o rigor, a dureza e os castigos. 0 que faz com que os alunos não queiram mais vir à escola (LA SALLE, 2012, v. 3, p. 195).

La Salle, em síntese, está preocupado com a formação moral, espiritual e intelectual dos professores. Da mesma forma, propõe uma formação integral e integradora do aluno, busca conduzir os mestres pelos mesmos caminhos, fazendo com que eduquem conforme a capacidade intelectual do aluno e pelo exemplo comportamental do docente.

O segundo elemento do pressuposto pedagógico, e que nos interessa resgatar na problematização da qualidade de ensino, é o aspecto metodológico. Adotando a modalidade coletiva de ensino, La Salle expõe uma série de regras de organização, comportamentos e didáticas de como deve ser conduzido o fazer pedagógico. Vejamos a recomendação dada aos professores em relação à confecção dos cartazes: "Cada cartaz terá seis linhas e cada linha, cinco letras. As letras unidas e ligadas entre si constituem como uma única letra, por exemplost, sl, fle outras que, em cada linha, ocupam somente o lugar de uma letra" (2012, v. 3, p. 238).

A metodologia descrita no Guia das Escolas Cristãs garante a uniformidade do ensino, bem como a sua replicação. Todos os professores praticam os mesmos rituais e assim conseguem garantir que a escola vá bem, ou seja, garantem a qualidade por meio da atração, conservação e progressão dos alunos em um sistema de ensino constituindo uma rede de escolas e não apenas escolase mestres isolados. A padronização permite a universalização do ensino de qualidade, servindo, portanto, para possibilitar e ampliar a liberdade de ensinar e aprender.

\section{Pressupostos econômicos}

É provável que durante a vigência do PNE 2011-2020, a pesquisa em educação no Brasil se aproxime dos pesquisadores da economia e da administração que compreendem o financiamento da educação como investimento na infraestrutura da sociedade do conhecimento. A Educação é um investimento público que implica ganho na produtividade, calculada como aumento do PIB ao longo de um ano:

ao gastar R $\$ 1,00$ em educação pública, o PIB aumentará em $\mathrm{R} \$ 1,85$, pelo simples processo de multiplicação da renda que esta atividade propicia. Enquanto isso, $\mathrm{R} \$ 1,00$ de produtos agropecuários ou oriundos da indústria extrativa de minérios que são exportados gera R \$1,4 de PIB para o País (ABRAHÃ0; MOSTAFA, HERCULANO, 2011, p. 10).

Outro cálculo apresentado por Neri (2011, p. 59) reafirma o tratado acima:

JereBerhman, do Banco Interamericano de Desenvolvimento (BID), demonstra que, para cada ano adicional de estudo, a expectativa de vida sobe dois anos, 0 crescimento populacional cai 0,26 ponto percentual (p.p.), as exportações aumentam 0,7 p.p. e 0 crescimento da renda per capita sobe 0,35 p.p. É difícil imaginar investimento, social ou privado, mais rentável do que uma criança passar de ano aprendendo.

A pesquisa em educação necessita reconhecer a educação também como um negócio, não no sentido da apropriação individual imediata do lucro, pelo contrário, no sentido de criação das condições adequadas para uma apropriação individual e coletiva a longo prazo da riqueza social. O idealismo das pessoas que se comprometem com a educação é necessário para empolgar uma turma na sala de aula, mas talvez nos atrapalhe porque nossa moralidade resiste a pensar na hipótese de uma educação lucrativa. Precisamos, no entanto, reconhecer que a educação pública é um negócio que universalizado adquire estatura moral, como atestou La Salle. O ganho econômico, a possibilidade de ascensão social era um dos seus principais argumentos para convencer as famílias, o próprio clero e os governantes das vantagens de investir na educação. Conforme La Salle (2012, v.3, p. 197) "Quando os pais retiram os filhos muito pequenos da escola ou quando não estão suficientemente instruídos, para fazê-los trabalhar, é preciso [fazer]-Ihes compreender que os prejudicarão muito e que, para lhes fazer ganhar pouca coisa, privamo-nos de vantagem bem mais considerável". 


\section{Conclusão}

Diante da análise das teses, dissertações e artigos, percebe-se o tema da qualidade do ensino como fundamental para o campo da educação. Os trabalhos analisados procuram lidar com um elemento novo, que são as avaliações externas da aprendizagem, as quais procuram identificar as escolas que vão bem e a partir daí, através de pesquisas de campo, nas escolas com os melhores resultados, identificar os fatores que geram a qualidade nas escolas.

Finalmente, parece-nos que para avançar nas pesquisas educacionais no Brasil do século XXI precisamos encarar sem receios ou pruridos politicamente corretos a questão científica formulada por Durkheim no início do século XX e da constituição da escola laica:

[...] se, para racionalizar a moral e a educação moral, se resolve retirar da disciplina moral tudo aquilo que é religioso, sem se colocar nada em seu lugar, corre-se o risco de também retirar elementos propriamente morais. E, então, sob o nome de moral racional não se teria mais do que uma moral empobrecida e desbotada. [...] É preciso em uma palavra, descobrir os equivalentes racionais dessas noções religiosas que, durante muito tempo, serviram de veículo às ideias morais mais essenciais (DURKHEIM, 2008, p. 24-25).

Um debate acadêmico sobre três pontos que caracterizam divergências políticase epistemológicas entre os pesquisadores em educação nos parece capaz de avançar na qualificação pedagógica da luta política pela qualidade da educação:

a) A pesquisa sobre política educacional precisa perder algumas crenças que se colocaram no lugar daquelas religiosas que perdemos. Apesar da contribuição da religião cristã para a educação, a pesquisa em educação criou problemas com a fé religiosa que talvez não ajudem no esforço racional pela melhoria da qualidade na educação. Uma dessas crenças é ignorar a contribuição dos pedagogos cristãos como La Salle, Comenius, Freire, Lutero e tantos outros. Outra é a crença ingênua e fundamentalista na oposição entre escola pública e escola confessional, difundindo a hipótese falsa de que a educação privada é melhor que a pública porque aquela é paga e esta é gratuita, esquecendo-nos da velha piada acadêmica dos cientistas políticos: não existe almoço grátis! Esquecendo-nos do próprio IDEB que aponta algumas escolas públicas como as melhores do país.

b) Parece-nos que os docentes da Educação Básica e também pesquisadores sustentam uma fé inabalável na LBD e uma "ira santa" contra os políticos que, afinal, escreveram a LDB. Um exemplo é a crença nos princípios da educação nacional afirmados no artigo $3^{\circ}$ da LDB. Amaioria dos pesquisadores e dos professores não consegue justificar estes princípios. Eles são assumidos dogmaticamente, sem uma justificação razoável. A noção de igualdade vem da fé cristã que forjou a cultura judaico-cristã ocidental. A fé cristã criou uma justificação popularmente convincente para o princípio da igualdade: a morte de Cristo na cruz por todas as pessoas pecadoras. Os princípios liberais do nosso artigo $3^{\circ}$ foram formulados por Durkheim no curso de Pedagogia na Sorbonne em 1902-1903 no seu esforço racional de livrar a educação pública de suas origens religiosas e, ao mesmo tempo, sem perder o poder justificador da fé em Deus para conteúdos morais necessários à vida republicana. Não parece que Durkheim tenha tido mais sucesso que La Salle. A república parece que ainda não encontrou substituto capaz de mobilizar o espírito humano para a prática da justiça na esfera política e pública com a força mobilizadora da fé cristã.

c) O amor pelas crianças justifica qualquer investimento público na sua boa educação. As ciências da educação têm dificuldades para expressar esse amor incondicional pelas crianças e sobre ele produzir sua ciência. Como anuncia Freire (1987) no fimdo Pedagogia do Oprimido anuncia sua esperança de que se "nada ficar destas páginas, algo, pelo menos, esperamos que permaneça: nossa confiança no povo. Nossa fé nos homens e na criação de um mundo em que seja menos difícil amar". Gadotti (1985) refletiu sobre o amor pelas crianças, Maturana (2011, p. 183-186) escreveu um breve e provocativo capítulo "Reflexões sobre o amor" tentando demonstrar que é o amor que nos diferencia dos animais e não a razão. Todo o esforço intelectual, organizacional e espiritual de La Salle para a qualificação da educação nasceu deseu amor incondicional pelas crianças e pelos educadores dessas crianças. A escola republicana, laica e gratuita é capaz e precisa capacitar-se para amar suas crianças. 
Os diretores/gestores das escolas lassalistas, por tradição institucional, procuram estar atentos aos avanços que vem ocorrendo no campo da educação e, seguindo a tradição de La Salle e dos primeiros Irmãos, procuram interpretar a vontade de Deus para a educação no século XXI, ou seja, buscam através da releitura crítica dos escritos de La Salle, reelaborar os principais conceitos da educação do seu tempo, para que possam atender às necessidades atuais das crianças.

Por outro lado, os diretores/gestores das escolas laicas que devem zelar pela qualidade do ensino, instrumento fundamental para o desenvolvimento de pessoas capazes de exercerem seus direitos, comprometidas com o melhoramento das suas comunidades e com a transformação do país em uma nação mais justa e igualitária. As escolas laicas encontram em La Salle um aliado político e pedagógico que deixou um legado que tem contribuído significativamente para o desenvolvimento da educação. Os diretores/gestores de todas as escolas podem buscar em La Salle uma fundamentação teórica, humana e espiritual se quiserem para resgatar conceitos pedagógicos decorrentes do amor pelas crianças, empenhando-se para fazer com que as escolas andem sempre bem, através da boa gestão escolar e das melhores opções pedagógicas. Dessa forma, será possível, por meio da boa educação, vislumbrar um futuro de mais esperança para as crianças, os jovens e os adultos.

\section{Referências}

ABRAHÃO, J.; MOSTAFA, J.; HERCULANO, P. Gastos com a Política Social: alavanca para o crescimento com distribuição de renda.). Comunicados do IPEA N 75, Brasília, 03/02/2011. Em: http://www.ipea.gov.br/ portal/images/stories/PDFs/comunicado/110203_comunicadoipea75.pdf, acesso em 11/11/2011.

AMORIM, M. D. A qualidade da Educação Básica no PDE: Uma análise a partir do Plano de Ações Articuladas. 2011. 165 f. Dissertação (Mestrado em Educação). Programa de Pós-Graduação em Educação da Faculdade de Educação da Universidade Federal da Grande Dourados, Dourados, 2011. Disponível em: <http:// www.ufgd.edu.br/faed/mestrado-educacao/dissertacoes/milenediasamorim>. Acesso em: 23 out. 2014.

BARDIN, L. Análise de conteúdo. Ed. rev. e ampl. São Paulo: Edições 70, 2011.

CASAGRANDE, C. A. (Org.). Ensinar a bem viver. Canoas, RS: Ed. do Unilasalle, 2011.

CNE/CEB. Conselho Nacional de Educação/Câmara de Educação Básica. Parecer $\mathbf{n}^{\circ} \mathbf{8 / 2 0 1 0}$, aprovado em 5 de maio de 2010. Estabelece normas para aplicação do inciso IX do artigo $4^{\circ}$ da Lei n 9.394/96 (LDB), que trata dos padrões mínimos de qualidade de ensino para a Educação Básica pública. Disponível em: http://portal.mec. gov.br/index.php?option=com_docman\&task=doc_download\&gid=5368\&ltemid=, acesso em 02 jun. 2015.

DURKHEIM, É. A educação moral. Rio de Janeiro: Vozes, 2008.

Freire, P. Pedagogia do oprimido, $17^{\mathrm{a}}$. ed. Rio de Janeiro, Paz e Terra, 1987

GADOTTI, M. Dialetica do amor paterno: Do amor pelos meus filhos ao amor por todas as criancas. 1. ed. São Paulo: Cortez, 1985.

GAUTHIER, C.; TARDIF, M. (Orgs.).A pedagogia: teorias e práticas da antiguidade aos nossos dias atuais. Petrópolis, RJ: Vozes, 2010.

GIL, A. C. Como Elaborar Projetos de Pesquisa. 5. ed. São Paulo: Atlas, 2010.

HENGEMÜLE, E. Educação centrada no aluno. In: FOSSATTI, Paulo; HENGEMÜLE, Edgard; Educação lassaliana: que educação?. Canoas: Unilasalle, Salles, 2007.

_. La Salle, uma leitura de leituras: o padroeiro dos professores na história da educação. Canoas, RS: Centro Universitário La Salle, [199-?].

IPEA. Uma análise da carga tributária bruta e das transferências de assistência e previdência no Brasil, no período 1995-2009: Evolução, composição e suas relações com a regressividade e a distribuição de renda. Texto para Discussão, n. 1464, Brasília, IPEA, jan. 2010. Disponível em http://www.ipea.gov.br/portal/images/ 
stories/PDFs/TDs/td_1464.pdf, acesso em 02 jun. 2015.

KLAUCK, G. A. C. Indicadores de qualidade de ensino: Estudo em escolas destaque no IDEB. 2012. $185 \mathrm{f}$. Dissertação (Mestrado em Educação). Programa de Pós-Graduação em Educação da Faculdade de Educação da Universidade Federal da Grande Dourados, Dourados, 2012. Disponível em: <http://www.ufgd.edu.br/faed/ mestradoeducacao/dissertacoes/giseliaparecidacaparrosklauck> Acesso em: 23 out. 2014.

LA SALLE, J. B. Cartas. In: __ Obras completas de São João Batista de La Salle. Canoas: Unilasalle, 2012.v. 1.

LA SALLE, J. B. Guia das Escolas Cristãs. In: Obras completas de São João Batista de La Salle. Canoas, RS: Ed. do Unilasalle, 2012, p 7-317. v. 3.

LA SALLE, J. B. Meditações para o tempo de retiro. In: Obras completas de São João Batista de La Salle. Canoas, RS: Ed. do Unilasalle, 2012, p. 433-483. v. 2-B.

LA SALLE, J. B. Meditações sobre as principais festas do ano. In: Obras completas de São João

Batista de La Salle. Canoas, RS: Ed. do Unilasalle, 2012, p. 183-411. v. 2-B.

LA SALLE, J. B. Memória dos Começos. In: Obras completas de São João Batista de La Salle. Canoas: Unilasalle, 2012.v. 1.

LA SALLE, J. B. Regras Comuns dos Irmãos das Escolas Cristãs. In: Obras completas de São João Batista de La Salle. Canoas, RS: Ed. do Unilasalle, 2012, p. 18-86. v. 2-A.

LAURAIRE, L. La Guía de lasEscuelas: Enfoque pedagógico, CahiersLasalliens, $\mathrm{n}^{\circ}$ 62, Roma: FrèresdesÉcolesChrétiennes, 2006.

MAILLEFER, F-E. Vida de São João Batista de La Salle. Canoas, RS: La Salle, 1991.

MARCHELLI, P. S. Expansão e qualidade da educação básica no Brasil. Cardernos de Pesquisa, São Paulo, v.40, n. 140, p. 561-585, mai/ago, 2010.

MATURANA R. H. A ontologia da realidade. 2. Imp. Belo Horizonte: Ed. UFMG, 2001.

MORALES, A. A. Espíritu y vida: elministerio educativo lasallista. Bogotá: Monserrate, 1990.

NARDI, E. L.; SCHNEIDER, M. da P.; RIOS, M. P. G. Qualidade na educação básica: ações e estratégias dinamizadoras. Educação \& Realidade, Porto Alegre, v. 39, n. 2, p. 359-390, abr./jun, 2014.

NERI, M. Equidade e Eficiências Educacionais. Aymará Cidades, Curitiba, n. 3, p. 58-59, abril/2011. Disponível em: http://www.fgv.br/cps/bd/clippings/nc0328.pdf, acesso em 11 nov. 2011.

PAZ, F. M. da.O índice de desenvolvimento da Educação Básica (IDEB): Um estudo do município de Santa Fé do Sul/SP. 2011. 189 f. Dissertação (Mestrado em Educação). Programa de Pós-Graduação em Educação da Faculdade de Filosofia e Ciências - UNESP, São Paulo, 2011. Disponível em: http://base.repositorio.unesp.br/ bitstream/handle/11449/96360/paz_fm_me_mar.pdf?sequence=1\&isAllowed=y. Acesso em: 23 out. 2014.

SALVETTI, T. A. S. A qualidade do ensino na dimensão da gestão democrática: Um estudo de caso na EMEB Alfredo Naime a partir do Indique. 2011. 86 f. Dissertação (Mestre em Ciências). Programa de PósGraduação em Administração da Universidade de São Paulo, Ribeirão Preto, 2011. Disponível em: <http://www. teses.usp.br/teses/disponiveis/96/96132/tde-03012012-155416/pt-br.php>. Acessoem: 23 out. 2014.

SAUVAGE, M.; CAMPOS, M. Reading Maillefer Today. AXIS: Journal of Lasallian Higher Education, Winona, v. 4, no. 1, 2013.http://axis.smumn.edu/index.php/axis/article/view/63/104. Acesso: 05 de ago. 2015.

SAVIANI, D. Formação de professores: aspectos históricos e teóricos do problema no contexto brasileiro. Revista Brasileira de Educação, Rio de Janeiro, v. 14, n. 40, p.143-155, jan./abr. 2009.

SILVA, H. A. da.Um estudo sobre o índice de desenvolvimento da Educação Básica (IDEB): Como as escolas públicas de Juiz de Fora melhoram o seu desempenho. 2012.93 f. Dissertação (Mestrado em Educação). Programa de Pós-Graduação em Educação da Universidade Federal de Juiz de Fora, Juiz de Fora, 2012. Disponível em: <http://www.ufjf.br/ppge/files/2012/05/Disserta\%C3\%A7\%C3\%A3o-IDEB.pdf>. Acesso em: 23 out. 2014. 
SOARES, J. F.; XAVIER, F. P. Pressupostos educacionais e estatísticos do Ideb. Educação \& Sociedade. Campinas, vol.34, n.124, p. 903-923,Jul./Set. 2013.

STRAUSS, A. L.; CORBIN, J. M. Pesquisa qualitativa: técnicas e procedimentos para o desenvolvimento de teoria fundamentada. 2. ed. Porto Alegre: Artmed: Bookman, 2008.

TAGLIAVINI, J.V.; PIANTKOSKI, M. A. João Batista de La Salle (1651-1719): um silêncio eloquente do educador católico que modelou a escola moderna. Revista HISTEDBR On-line, Campinas, n. 53, p. 16-40, out. 2013.

WESCHENFELDER, I. L. As dimensões na pedagogia de La Salle. Rio de Janeiro: Editora Autografia, 2015. 